\title{
Extraction Kinetics and Molecular Size Fractionation of Humic Substances From Two Brazilian Soils
}

\author{
Deborah Pinheiro Dick ${ }^{\mathrm{a}, *}$, and Peter Burba ${ }^{\mathrm{b}}$ \\ anstituto de Química, UFRGS, Av. Bento Gonçalves 9500, \\ 91501-970 Porto Alegre -- RS, Brazil \\ ${ }^{\mathrm{b}}$ Institute for Spectrochemistry and Applied Spectroscopy, \\ D-44139 Dortmund, Germany
}

\begin{abstract}
No presente trabalho foi estudada sistematicamente a extração de substâncias húmicas (SH) de um Oxisol e de um Mollisol do Sul do Brazil, empregando-se soluções de $\mathrm{NaOH} 0.1$ e $0.5 \mathrm{~mol} \mathrm{~L}^{-1}$ e de $\mathrm{Na}_{4} \mathrm{P}_{2} \mathrm{O}_{7} 0.15 \mathrm{~mol} \mathrm{~L}^{-1}$ a pH 7. A cinética e o rendimento de extração foram monitorados através de espectroscopia UV/Vis. Os ácidos húmicos $(\mathrm{AH})$ e os ácidos fúlvicos (AF) foram fracionados segundo o seu tamanho por ultrafiltração em multi-estágios (seis frações) no intervalo de peso molecular de 1 a $100 \mathrm{kDa}$. Os resultados obtidos mostraram que o rendimento de extração de SH dependeu não apenas do extrator, porém também do tipo de solo. Em 3 h, aproximadamente $90 \%$ de SH solúveis foram extraídas por ambos os métodos e pouca ou nenhuma modificação estrutural foi constatada conforme a constância do valor da razão $\mathrm{E}_{350} / \mathrm{E}_{550}$, ficando evidente porém uma cinética complexa de extração. No Mollisol, a extração com pirofosfato foi mais efetiva, sugerindo que grande parte das SH ocorreram como macromoléculas ligadas aos argilo-minerais e entre si através de pontes catiônicas. No Oxisol o maior rendimento foi obtido pelo método alcalino, provavelmente devido à fixação de $\mathrm{SH}$ nas superfícies dos óxidos via pontes de hidrogênio e/ou complexação de superfície. Em geral, as SH extraídas com solução de pirofosfato apresentaram peso molecular médio superior ao das SH extraídas pelo método alcalino.
\end{abstract}

In the present study, the extraction behaviour of humic substances (HS) from an Oxisol and a Mollisol from South Brazil, by using 0.1 and $0.5 \mathrm{~mol} \mathrm{~L}^{-1} \mathrm{NaOH}$ and $0.15 \mathrm{~mol} \mathrm{~L}^{-1}$ neutral pyrophosphate solutions, respectively, was systematically studied. The kinetics and efficiency of HS extraction were evaluated by means of UV/Vis spectroscopy. The isolated humic acids (HA) and fulvic acids (FA) were size-classified by multistage ultrafiltration (six fractions) in the molecular weight range of 1 to $100 \mathrm{kDa}$. The obtained data show that the HS extraction yield depended not only on the extractant, but also on the soil type. Within $3 \mathrm{~h}$ approximately $90 \%$ of the soluble HS could be extracted following complex extraction kinetics by both methods and none or little structural modification was verified as observed from their stable extinction ratio $\mathrm{E}_{350} / \mathrm{E}_{550}$. In the Mollisol the pyrophosphate extraction was more effective, suggesting that a great part of HS occurred as macromolecules bonded to clay minerals and aggregated between themselves through cationic bridges. In the Oxisol a higher HS yield was verified with the alkaline method, presumably due to HS fixation onto the oxide surface by H-bonds and/or surface complexation reactions. In general, HS extracted by the pyrophosphate procedure showed higher molecular weights than those extracted by $\mathrm{NaOH}$.

Keywords: humic substances, oxisol, mollisol, molecular-weight fractionation, extraction kinetics

\section{Introduction}

The main mass of refractory organic carbon in soils is concentrated in humic substances (HS), a polydisperse mixture of related macromolecules formed by microbial degradation of plant remnants ${ }^{1}$. HS in soils occur mainly: a) as insoluble macromolecular aggregates, b) as macromolecules bound together by di- and tri-valent cations (e.g.

*E-mail: dpdick@ifl.if.ufrgs.br 
$\mathrm{Ca}^{2+,}, \mathrm{Al}^{3+}$ and $\mathrm{Fe}^{3+}$ ), c) associated with clay minerals through cationic bridges, H-bonds and ligand exchange reactions, d) occluded in the interlayers of expanding-type clay minerals ${ }^{2}$. The abundance of each form and the quality of HS depends greatly on the soil type and soil mineralogy.

The association of HS with Al- and Fe-oxide surfaces has been investigated by means of sorption studies ${ }^{3,4,5}$ and selective extractions ${ }^{6,7}$. It was observed that pedogenic $\mathrm{Al}$ and Fe oxides exerted a stabilizing effect on the soil humic matter ${ }^{8}$. The interaction between HS and Fe-oxides surfaces occurs via ligand exchange of surface $-\mathrm{OH}$ or $-\mathrm{OH}_{2}$ with organic anions and via $\mathrm{H}$-bonds ${ }^{2}$. On the other hand, the association of HS with clay minerals occurs mainly via cationic bridges $^{2}$. An enhancement of HS adsorption on montmorillonite, kaolinite and illite has been observed by the addition of $\mathrm{Ca}^{2+9,10}$ and of $\mathrm{Al}^{3+11}$.

A differentiating analysis of HS in soils by a variety of chemical and spectroscopic methods available for this purpose, generally requires their preceding isolation ${ }^{1}$. The extractant conventionally used for HS isolation from soil samples is $\mathrm{NaOH}$ solution, which is also the most efficient one $^{12}$. Since alkaline extraction may cause chemical alteration of the $\mathrm{HS}$, the $\mathrm{Na}_{4} \mathrm{P}_{2} \mathrm{O}_{7}$ solution, a milder solvent, is also frequently employed ${ }^{12,13,14,15}$. The extractability of soil organic matter (SOM) with $\mathrm{NaOH}$ solution and with pH-unadjusted $\mathrm{Na}_{4} \mathrm{P}_{2} \mathrm{O}_{7}$ solution from soils widely differing in pedological characteristics has been investigated ${ }^{13}$. In that study, variations in extraction yield and quality of HS for the different samples were related to the different mineralogy. In pyrophosphate extracts of SOM from Oxisols, suspended particles with the same Al- and Fe-mineralogy of the corresponding clays were observed ${ }^{6}$. On the contrary, pyrophosphate extracts of Alfisols contained Fe and $\mathrm{Al}\left(0.3\right.$ to $6.1 \mathrm{~g} \mathrm{Fe} \mathrm{kg}^{-1}$ and 0.3 to $\left.10.9 \mathrm{~g} \mathrm{Al} \mathrm{kg}^{-1}\right)$ mainly complexed to SOM.

Another important parameter considerably influencing the reaction of HS in soil is their molecular size and the functionalities contained in the different HS fractions ${ }^{2}$. Therefore a number of recent studies have focused on the molecular size differentiation of HS in both soils and aquatic systems. Humic acids (HA) were fractionated from an Andosol and from a Cambisol by successive gel permeation chromatography (GPC) and it was verified that the fractions differed chemically ${ }^{16}$. Recently, a multistage ultrafiltration (MST-UF) device was adapted to fractionate aquatic $\mathrm{HS}$ and it was verified that HS fractions of higher molecular size exhibited a different composition from that of the smaller ones ${ }^{17}$. Moreover, it was observed that the HS molecular size distribution determined with MST-UF and with GPC were in good agreement in the range of 1-50 $\mathrm{kDa}^{18}$.

The present study on HS in two Brazilian soils of different mineralogy (Oxisol and Mollisol) was concentrated on the HS extraction behaviour operationally influ- enced by the applied extractants $\left(\mathrm{NaOH}, \mathrm{Na}_{4} \mathrm{P}_{2} \mathrm{O}_{7}\right)$. The main objectives were: (i) to investigate the extraction kinetics of HS from soils of different mineralogy; and (ii) to evaluate the influence of the extraction procedures used and the soil mineralogy on the yield and the molecular size distribution of the HS under study. For the latter purpose MST-UF already successfully applied for size classification of aquatic HS had to be adapted for the fractionation of dissolved soil $\mathrm{HS}^{17}$.

\section{Materials and Methods}

\section{Soils}

Humic substances were extracted from the A-horizon (0 to $10 \mathrm{~cm}$ ) of an Oxisol and of a Mollisol from Rio Grande do Sul state, Brazil. The Oxisol, located in Santo Angelo, was under agricultural use (crop rotation oat/soja), contained $27 \mathrm{~g} \mathrm{~kg}^{-1}$ soil of organic Carbon, and its clay mineralogy was dominated by Fe-oxides and kaolinite ${ }^{19}$. The Mollisol, located in Rio Pardo, was under native vegetation, contained $21 \mathrm{~g} \mathrm{~kg}^{-1}$ soil of organic carbon, and its clay mineralogy consisted mainly of smectites and kaolinite ${ }^{20}$.

\section{Kinetic tests}

Three extractant solutions were employed: a) $0.1 \mathrm{~mol}$ L-1 NaOH; b) $0.5 \mathrm{~mol} \mathrm{~L}-1 \mathrm{NaOH}$ and C) $0.15 \mathrm{~mol} \mathrm{~L}^{-1}$ $\mathrm{Na}_{4} \mathrm{P}_{2} \mathrm{O}_{7}$ adjusted to $\mathrm{pH} 7$. In a $10 \mathrm{~mL}$ centrifuge tube, 5 $\mathrm{mL}$ of extractant solution was added to $c a .240 \mathrm{mg}$ soil. During $24 \mathrm{~h}, 3 \mathrm{~mL}$ of the supernatant solution were collected periodically (10 min., 30 min., $1 \mathrm{~h}, 2 \mathrm{~h}, 3 \mathrm{~h}, 4 \mathrm{~h}, 6 \mathrm{~h}$ and $24 \mathrm{~h}$ ) for UV/Vis spectroscopy measurements and returned again to the tube. After $24 \mathrm{~h}$ the extract was separated from the soil by centrifugation at $2000 \mathrm{rpm}$ and a second and a third 24 h-extraction were carried out. The $\mathrm{pH}$ level was measured in each extract after $24 \mathrm{~h}$.

\section{Extraction and isolation of $H A$ and FA}

HS were extracted separately with $0.5 \mathrm{~mol} \mathrm{~L}^{-1} \mathrm{NaOH}$ and with $0.15 \mathrm{~mol} \mathrm{~L}^{-1} \mathrm{Na}_{4} \mathrm{P}_{2} \mathrm{O}_{7}(\mathrm{pH} 7)$ solutions $(250 \mathrm{~mL}$ $/ 11 \mathrm{~g}$ soil) during $3 \mathrm{~h}$ under continuous shaking, based on Swift (1996). The HS extract separated by centrifugation was immediately acidified to $\mathrm{pH} 2$ with $0.1 \mathrm{~mol} \mathrm{~L}^{-1} \mathrm{HCl}$. After $24 \mathrm{~h}$, the precipitated HA was separated by centrifugation from the remaining FA solution, washed twice with distilled water and dried at room temperature in a desiccator over $\mathrm{P}_{4} \mathrm{O}_{10}$.

The obtained FA solution ( $\mathrm{pH} 2$ ) was run over a XAD-8 column and then eluted by a $0.1 \mathrm{~mol} \mathrm{~L}^{-1} \mathrm{NaOH}$ solution ${ }^{17}$. After neutralization by diluted $\mathrm{HCl}$ this $\mathrm{FA}$ concentrate was dried by rotatory-evaporation at $70^{\circ} \mathrm{C}$.

Fractionation of HA and FA by multistage-UF (MST-UF)

HA and FA were size-fractionated (6 fractions; F1: > 100, F2: 50-100, F3: 10-50, F4: 5-10, F5: 1-5, and 
F6: < $1 \mathrm{kDa}$ ) by using the multistage-UF technique of Burba et al. ${ }^{17} .10 \mathrm{~mL}$ of the humic substance solution under study (ca. $0.5 \mathrm{mg} \mathrm{mL}^{-1}, \mathrm{pH}$ 7) were pumped through the MST-UF device (Pall Filtron, OMEGA membranes based on polyethersulfone, $25 \mathrm{~mm}$, nominal molecular weight cut-off: 100, 50, 10, 5 and $1 \mathrm{kDalton}$ ) and then washed with $10 \mathrm{~mL}$ of high purity water (Millipore MilliQ system) ${ }^{18}$.

The collected HS fractions ( $1 \mathrm{~mL}$, each) were washed out quantitatively with $2 \mathrm{~mL}$ water, and kept for UV/VIS spectroscopy. Their relative concentration $(\%)$ of each fraction was calculated by relating its absorbance at $450 \mathrm{~nm}$ to the absorbance in the same wavelength of the HS solution to be fractionated $(100 \%)^{17}$.

\section{UV/Vis spectroscopy}

UV/Vis spectra of the extracted HS ( $\mathrm{pH} 13$ and $\mathrm{pH}$ 7), of the fulvic acids (FA), of the humic acids (HA) and of their respective MST-UF-fractions were recorded in the range of 200-700 nm (Scanning double-beam spectrometer Varian Cary 1/3). For the kinetic tests, the absorbances of the first pyrophosphate-extracts were measured at $\mathrm{pH} 7$ within $24 \mathrm{~h}$. The values were then corrected for $\mathrm{pH} 13$, employing a calibration curve calculated from the measurements at $\mathrm{pH} 7$ and at $\mathrm{pH} 13$, obtained in a parallel experiment.

The spectroscopic method for the determination of HS distribution in the UF-MS tests had been calibrated by Burba et al. ${ }^{17}$, and thus it was also employed in the kinetics tests. The relative amount of extracted HS was estimated from the subtraction $\left[\mathrm{E}_{450}-\mathrm{E}_{700}\right]$, where $\mathrm{E}_{450}$ and $\mathrm{E}_{700}$ are the absorbances at $450 \mathrm{~nm}$ and $700 \mathrm{~nm}$, respectively. The determination of total organic carbon via oxidative methods, could not be employed for the calculation of HS concentration, because this chemical method is destructive and hence would render impossible the monitoring of the kinetics of the extraction in the same extract.

The $\mathrm{E}_{450}$ was choosen because absorbance in this region is concentration dependent ${ }^{23}$ and less influenced by HS strucutral and chemical characteristics than at the shorter wavelengths ${ }^{28}$, since the different chromophores absorb in the UV- region ${ }^{1,21}$. Simultaneously, the $\mathrm{E}_{450}$ absorbances were generallly above the error limit of the experimental measurements, in contrast to the absorbances at larger wavelengths in some samples. The $\mathrm{E}_{700}$ is preferably caused by small amounts of remaining particles in the sample solution, and its subtraction was employed as a correction of the $\mathrm{E}_{450}$ values.

From the UV/Vis data, the ratio $\mathrm{E}_{350} / \mathrm{E}_{550}$ (absorbance at 350 and $550 \mathrm{~nm}$, respectively) was calculated. These wavelengths were choosen instead of the usually employed $\mathrm{E}_{465} / \mathrm{E}_{665}$, because the absorbance at $665 \mathrm{~nm}$ was sometimes too low, that the values could not be considered. In the present work, it is proposed that the shift of the $\lambda_{\max }$ of the chromophores to longer wavelengths due to molecular condensation $^{21}$ can also be qualitatively estimated from the ratio $\mathrm{E}_{350} / \mathrm{E}_{550}$. Like the ratio $\mathrm{E}_{465} / \mathrm{E}_{665}$, the proposed index should be adequate for comparison among the studied samples.

\section{Results and Discussion}

\section{Extraction kinetics and method yield}

The plot of [ $\left.\mathrm{E}_{450}-\mathrm{E}_{700}\right]$, which expresses the amount of solubilized HS, as a function of time, shows that the HS extraction proceeded rather fast within the first $10 \mathrm{~min}$ (Fig. 1). The $\mathrm{pH}$ constancy and the high ionic force $\left(0.15 \mathrm{~mol} \mathrm{~L}^{-1}\right.$ in pyrophosphate, 0.1 and $0.5 \mathrm{~mol} \mathrm{~L}^{-1}$ in the alkaline solutions) in each extract during the $24 \mathrm{~h}$, assure that the absorbance results are related to the amount of extracted HS rather than to HS with different macromolecular shape.

In both samples the $0.1 \mathrm{~mol} \mathrm{~L}^{-1} \mathrm{NaOH}$ extractant solution reached its maximum extraction yield, MEY, after $2 \mathrm{~h}$. The MEY corresponds to $100 \%$ of the extraction amount of HS after $24 \mathrm{~h}$. Within $3 \mathrm{~h}$, the pyrophosphate solution extracted ca. 80\% (Oxisol) and 95\% (Mollisol) of its respective MEY's, and $0.5 \mathrm{~mol} \mathrm{~L}^{-1} \mathrm{NaOH}$ extractant reached $90 \%$ (Oxisol) and $80 \%$ (Mollisol) of its MEY's (Fig. 1).

In the Oxisol the $0.5 \mathrm{~mol} \mathrm{~L}^{-1} \mathrm{NaOH}$ solution extracted a higher amount of HS than pyrophosphate within $3 \mathrm{~h}$. On the contrary, a higher HS yield by pyrophosphate was obtained in the Mollisol. This last result aggrees with those verified in a Mollisol ${ }^{14}$ and in a Gleysol ${ }^{15}$ by sequential HS extractions with pyrophosphate solutions at different $\mathrm{pH}$ levels.

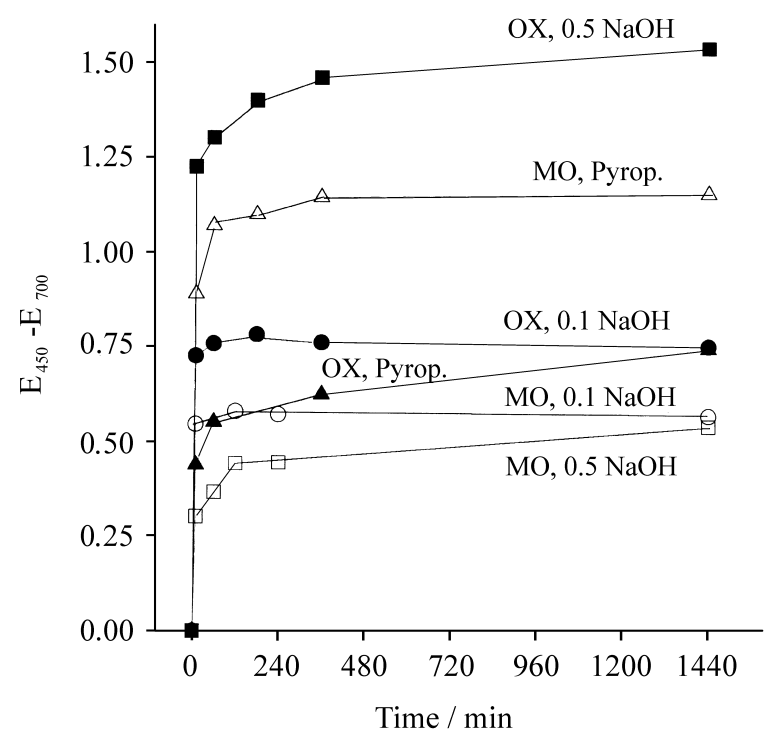

Figure 1. Variation of E450-E700 with time, of HS extracted from the Oxisol (OX) and from the Mollisol (MO) with $0.1 \mathrm{~mol} \mathrm{~L}^{-1} \mathrm{NaOH}(0.1$ $\mathrm{NaOH})$, with $0.5 \mathrm{~mol} \mathrm{~L}^{-1} \mathrm{NaOH}(0.5 \mathrm{NaOH})$ and with $0.15 \mathrm{~mol} \mathrm{~L}^{-1}$ Pyrophosphate (Pyrop.) solutions. 
Due to the complex and heterogeneous chemical nature of humic substances, different sorption/retainment mechanisms in the environment are likely to act simultaneously ${ }^{22}$. Our findings suggest that the extent of each mechanism is strongly influenced by the soil mineralogy, which affects the extraction efficiency of a given method.

The $\mathrm{Na}_{4} \mathrm{P}_{2} \mathrm{O}_{7}$ extraction solubilizes HS mainly by disrupting cationic bridges of polyvalent cations which bind organic molecules between themselves or link them to the negative charged surface of minerals ${ }^{2}$. The pyrophosphate anion forms with such cations either insoluble precipitates (e.g. $\left.\mathrm{Ca}^{2+}\right)$ or soluble coordination compounds $\left(\right.$ e.g. $\mathrm{Al}^{3+}$ and $\left.\mathrm{Fe}^{3+}\right)$, leaving the negative sites on the organic molecules free for the (abundant) $\mathrm{Na}^{+}$ions. In the alkaline extraction, the $\mathrm{pH}$-dependent charge of the mineral surface as well of the HS, is converted to its negative form, and HS solubilization occurs due to repulsion between equally negative charged surfaces and formation of soluble HS salts. By this extraction, mainly $\mathrm{H}$-bonding and surface complexation interactions between HS and mineral surfaces are broken up ${ }^{2}$.

In view of the mineralogy of the two studied soil samples, it is not surprising that the pyrophosphate method showed a higher yield in the Mollisol, where minerals with permanent negative charge predominate. From the Oxisol, where the mineralogy consists mainly of Fe-oxides and kaolinite, the alkaline method extracted much more HS than the pyrophosphate one. Those results are indicative for the specificity of the two methods in solubilizing soil HS by different mechanisms.

The absorbance ratio $\mathrm{E}_{465} / \mathrm{E}_{665}$ of $\mathrm{HS}$ is a traditional parameter to estimate their humification degree and/or their molecular size ${ }^{21,23}$. Though, other ratios like $\mathrm{E}_{350} / \mathrm{E}_{450}{ }^{17}$ or $\mathrm{E}_{350} / \mathrm{E}_{550}$ can be used with the same purpose. In the present study, the variation range of the absorbance ratios $\mathrm{E}_{350} / \mathrm{E}_{550}$ from $10 \mathrm{~min}$ to $24 \mathrm{~h}$, of the extracted HS are shown in Table 1.

For all extracts, the values increased with time, and this fact is probably more related to a gradual enrichment in structures of lower molecular sizes in the two alkaline and in the pyrophosphate extracts, and less to a strong chemical modification. It has been reported that absorbance ratios vary inversely with the molecular size ${ }^{17,21}$. Furthermore, in an investigation of the influence of the oxidative atmosphere in the $\mathrm{NaOH}$ treatment, an increase on the oxidation

Table 1. Range of E350/E550 data from $10 \mathrm{~min}$ to $24 \mathrm{~h}$ of the HS extracted from the Oxisol (OX) and the Mollisol (MO).

\begin{tabular}{lcc}
\hline Treatment & $\mathrm{E}_{350} / \mathrm{E}_{550}-\mathrm{OX}$ & $\mathrm{E}_{350} / \mathrm{E}_{550}-\mathrm{MO}$ \\
\hline $\mathrm{NaOH} 0.1 \mathrm{~mol} \mathrm{~L}^{-1}$ & $5.7-5.9$ & $5.3-6.8$ \\
$\mathrm{NaOH} 0.5 \mathrm{~mol} \mathrm{~L}^{-1}$ & $8.1-9.6$ & $8.1-8.6$ \\
Pyrophosphate $0.15 \mathrm{~mol} \mathrm{~L}^{-1}$ & $7.8-8.8$ & $5.6-6.2$ \\
\hline
\end{tabular}

of $\mathrm{HA}$ and $\mathrm{FA}$ extracted under $\mathrm{O}_{2}$ was not observed when compared to those extracted from the same sample under an inert atmosphere ${ }^{24}$.

In both samples, within the first $3 \mathrm{~h}$ (data not shown here), the $\mathrm{E}_{350} / \mathrm{E}_{550}$ ratios of the two alkaline and of the pyrophosphate HS extracts increased no more than one unit, and because of that the $3 \mathrm{~h}$ long extraction was employed for the separation and isolation of HS that were further fractionated by MST-UF.

For each soil sample, the $0.5 \mathrm{~mol} \mathrm{~L}-1 \mathrm{NaOH}$ extract showed the highest $\mathrm{E}_{350} / \mathrm{E}_{550}$ ratio (Table 1), suggesting that this extracting agent solubilized HS with a smaller average molecular size. Probably, the rupture of the inter/intra-molecular hydrogen bonding of the HS in the $\mathrm{NaOH}$ solution accounts for the higher observed $\mathrm{E}_{350} / \mathrm{E}_{550}$ values. The same trend with $\mathrm{E}_{400} / \mathrm{E}_{600}$ ratio values has been observed by other authors ${ }^{13}$.

Another parameter hardly considered with respect to HS isolation from soil samples is its extraction kinetics which was assessed in the present study by means of $\left[E_{\max }-E_{t}\right] / E_{\max }$ as a function of the time, where $E_{\max }(450$ $\mathrm{nm}$ ) corresponds to the absorbance of the HS extract at 24 $h$ and $E_{t}$ to the absorbance at the time $t$. The shape of the extraction curves in Fig. 2 indicates that the HS solubilization from both soil samples by the two tested extractants is much more complex than a first order reaction. The same conclusion was reached by the investigation of the alkaline extraction of HS at different temperatures from brown coals, and in that work it was supposed that the opening of aromatic rings due to an alkaline oxidation, was responsible for the complex extraction kinetics ${ }^{25}$. Since in the present work, the alkaline as well as the neutral extraction data showed a similar behaviour, other factors might have influ-

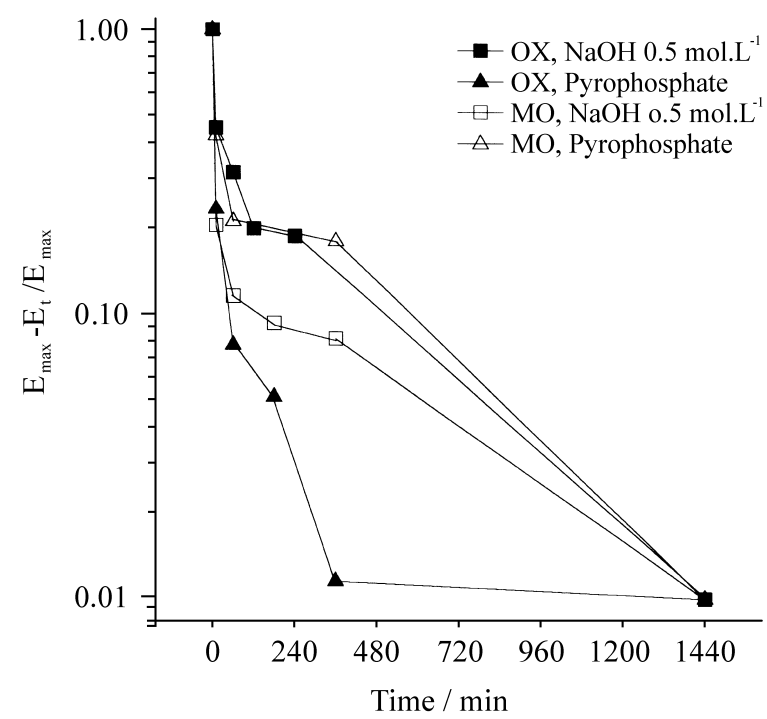

Figure 2. Variation of $\ln \left(E_{\max }-E_{t} / E_{\max }\right)$ with time of HS extracted from the Oxisol (OX) and from the Mollisol (MO) with $0.5 \mathrm{~mol} \mathrm{~L}^{-1} \mathrm{NaOH}$ and with $0.15 \mathrm{~mol} \mathrm{~L}^{-1}$ Pyrophosphate solutions. 
enced the extraction kinetics of HS in the Oxisol and Molisol.

\section{Consecutive extractions}

The extraction efficiency of the chosen HS extractants was studied by means of consecutive extractions, each consisting of a $24 \mathrm{~h}$-long period. As shown in Fig. 3, the greater part of the HS was extracted in the first stage (in the Molllisol by pyrophosphate and in Oxisol by $0.5 \mathrm{~mol} \mathrm{L-1}$ $\mathrm{NaOH}$ solutions) and continuously decreased after that. Furthermore, the different yields of the two methods in the first extraction are not compensated by the subsequent ones, and supports the considerations made previously about the selectivity of the two extractants tested.

Moreover, from the $\mathrm{E}_{350} / \mathrm{E}_{550}$ ratio of the HS extracts decreasing continuously in the consecutive extractions (Fig. 3), it can be suggested that the solubilization of chemically/structurally different HS fractions occured in each extraction stage.

\section{Molecular-size fractionation by MST-UF}

The fractionation of HA and FA by MST-UF into six molecular weight fractions was performed at $\mathrm{pH}$ value 7 and a constant electrolyte concentration of $0.05 \mathrm{~mol} \mathrm{~L}^{-1}$ $\mathrm{NaCl}$ based on experimental conditions optimized in Burba et $a l .{ }^{17}$. Afterwards, the HS molecular distribution (in \%) was determined according to Aster et al. ${ }^{18}$. The molecular size distributions of the studied HS are given in Fig. 4.

In general, the investigated FA were mainly found in the smaller fractions (F6 to F4) in contrast to the corre-



Figure 3. E450-E700 values for each of the three $24 \mathrm{~h}$-extractions of HS extracted from the Oxisol (OX) and from Mollisol (MO) with $0.5 \mathrm{~mol} \mathrm{~L}^{-1}$ $\mathrm{NaOH}$ and with $0.15 \mathrm{~mol} \mathrm{~L}^{-1}$ Pyrophosphate solutions. E350/E550 ratio values for each extraction are given above the column.

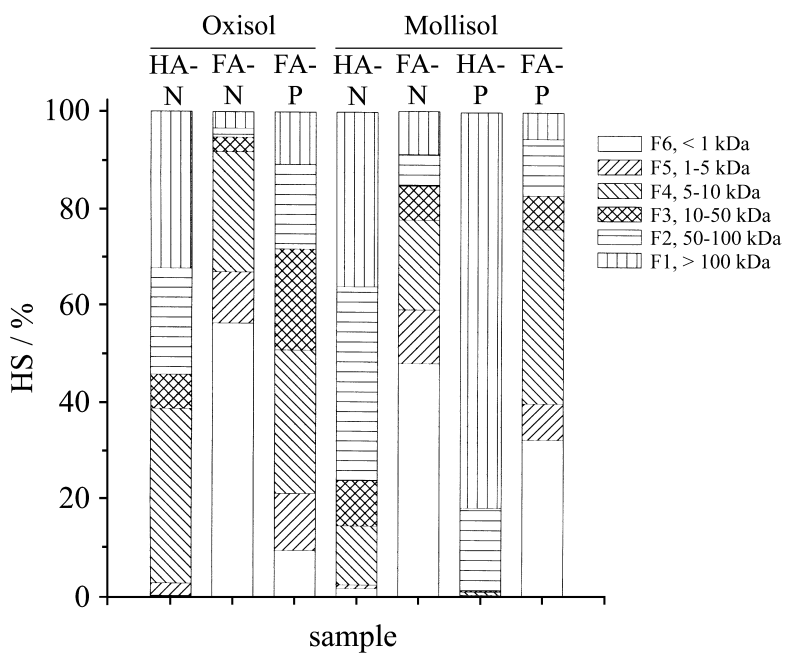

Figure 4. Molecular size distribution of the $\mathrm{HA}$ and FA extracted with $0.5 \mathrm{~mol} \mathrm{~L}^{-1} \mathrm{NaOH}(\mathrm{N})$ and with $0.15 \mathrm{~mol} \mathrm{~L}^{-1}$ Pyrophosphate (P) solutions.

sponding HA, whose main fractions were found between 50 and $100 \mathrm{kDa}$ and $>100 \mathrm{kDa}$ (F2 and F1, respectively). In both samples, the fraction F6 was more abundant in the FA extracted with $\mathrm{NaOH}$ when compared to the FA-P, indicating that the alkaline solution produced smaller FA molecules. Furthermore, in the Mollisol, HA-P was richer in fraction F1 than the corresponding HA-N (Fig. 4).

From the plot in Fig. 4 the nominal average molecular weight $\left\langle\mathrm{M}_{\mathrm{w}}\right\rangle$ presented by at least $50 \%$ of the HS can be estimated. For example, in the sample OX-HA-N, if the contents of HS were added from fraction F6 up to the bigger fractions, the value of $50 \%$ HS is already reached by the addition of fraction F2. In other words, in this sample, at least $50 \%$ of HS presented a molecular weight $\leq 100 \mathrm{kDa}$. The values obtained for these nominal $\left\langle\mathrm{M}_{\mathrm{w}}\right\rangle$ are given in Table 2 excepted for MO-HA-P where 77\% HS is concentrated in the fraction $\mathrm{F} 1$, and the $\left\langle\mathrm{M}_{\mathrm{w}}\right\rangle$ was classified as greater than $100 \mathrm{kDa}$.

Table 2. $\mathrm{pH}$ value $\left(\mathrm{pH}_{0}\right)$ and $\mathrm{E}_{350} / \mathrm{E}_{550}$ ratio of the initial solution and average molecular weight $\left\langle\mathrm{M}_{\mathrm{w}}\right\rangle$ of the humic acids (HA) and fulvic acids (FA) from the Oxisol (OX) and the Mollisol (MO).

\begin{tabular}{lccc}
\hline Sample & $\mathrm{pH}_{\mathrm{O}}$ & $\mathrm{E}_{350} / \mathrm{E}_{550}$ & $\left\langle\mathrm{M}_{\mathrm{W}}\right\rangle(\mathrm{kDa})$ \\
\hline OX-HA-N & 7.2 & 8.2 & $\leq 100$ \\
OX-FA-N & 7.2 & 15.4 & $\leq 1$ \\
OX-FA-P & 7.0 & 15.1 & $\leq 10$ \\
MO-HA-N & 7.3 & 8.4 & $\leq 100$ \\
MO-FA-N & 7.1 & 15.1 & $\leq 5$ \\
MO-HA-P & 6.8 & 4.0 & $>100$ \\
MO-FA-P & 7.1 & 8.5 & $\leq 10$ \\
\hline
\end{tabular}

Legend: - $\mathrm{N}$ : first 3 h-long $\mathrm{NaOH}$ extract; P: first 3 h-long pyrophosphate extract. 
The pyrophosphate-extracted HA and FA generally exhibited higher $\left\langle\mathrm{M}_{\mathrm{w}}\right\rangle$ and lower E350/E550 values than the corresponding $\mathrm{NaOH}$ extracted HS. (Table 2) .This result might be a hint that cationic bonds (broken by pyrophosphate) are formed preferably by larger HS molecules, while smaller moieties interact mainly through $\mathrm{H}$-bonds and ligand exchange reactions. It has been verified that pyrophosphate extracted a higher molecular weight organic matter than $\mathrm{NaOH}$ solution ${ }^{13}$. Some authors ${ }^{26}$ proposed that $\mathrm{Al}^{3+}$ and $\mathrm{Fe}^{3+}$ are preferably associated with larger humic molecules, since pyrophosphate, which extracted HS of higher molecular weight, also has an affinity for those metals. Furthermore, it was verified that HS molecules > $50 \mathrm{kDa}$ formed stronger complexes with $\mathrm{Mn}(\mathrm{II})$, $\mathrm{Zn}(\mathrm{II}), \mathrm{Al}(\mathrm{III})$ and $\mathrm{Fe}(\mathrm{III})$ than the smaller ones ${ }^{18}$. On the other hand, the possibility that in the present work, the alkaline solution disrupted further inter-molecular H-bonds which were resistant to pyrophosphate treatment, cannot be excluded.

Practically no HA was extracted with pyrophosphate in the Oxisol, suggesting that in this Fe-oxide rich sample, the interaction between humic acid matter and mineral surfaces was mainly based on strong ligand-exchange and/or H-bonds. The $\mathrm{HA}$ extracted with $\mathrm{NaOH}$ in the first 3 h-extraction (HA-N) showed similar $\left\langle\mathrm{M}_{\mathrm{w}}\right\rangle$ values in both soils.

For each studied HS sample, the E350/E550 ratio significantly decreases with the increasing molecular weight of the MST-UF fractions, but the values observed in comparable molecular weight fractions strongly differ among the samples (Table 3), indicating that structural/chemical characteristics also influence the obtained E350/E550 ratios. A similar inverse relationship between $\mathrm{E}_{350} / \mathrm{E}_{550}$ ratio and molecular size of fractionated aquatic HS has already been verified ${ }^{16,17}$. It was also proposed the $\mathrm{E}_{460} / \mathrm{E}_{660}$ ratio as a qualitative indicator of HS molecular size of different materials, because of the strong dependence of the UV/Vis spectra inclination on other parameters ${ }^{27}$.
In the Oxisol (excluding the fraction $5-10 \mathrm{kDa}$ ) the FA's showed generally a higher value for E350/E550 ratio than the HA's (Table 3), as is usually observed for the classical $\mathrm{E}_{460} / \mathrm{E}_{660}$ ratio. In the Mollisol, the pyrophosphate extracted HS (either FA or HA) showed the smallest E350/E550 ratio in the corresponding fractions.

\section{Conclusions}

From our study comparing systematically the extraction behaviour of HS in two Brazilian soils of different mineralogy, the following conclusions can be drawn:

(1) The extraction yield of HS not only depended on the extractant chosen but also strongly on the soil type. According to their solubilization mechanisms, the extractants solubilized different HS fractions but the yields of the tested procedures (alkaline and neutral pyrophosphate extraction, respectively) were partially equivalent.

(2) Approximately $90 \%$ or more of the soluble soil HS studied could be extracted within $3 \mathrm{~h}$ following complex extraction kinetics. No structural modification of HS was observed during this extraction period, as indicated by the ratio $\mathrm{E}_{350} / \mathrm{E}_{550}$ data.

(3) The absorbance ratio E350/E550 of the extracted HS differed considerably, depending on the chosen extractant.

(4) Considering the extraction mechanism of the two employed methods, it can be concluded that in the Mollisol, the greater part of HS occured as macromolecules aggregated between themselves and bonded to clay minerals through cationic bridges (pyrophosphate extractable HS), while in the Oxisol the HS were presumably associated with oxide surfaces preferentially through $\mathrm{H}$-bonds and/or ligand exchange reactions ( $\mathrm{NaOH}$ extractable $\mathrm{HS}$ ).

(5) Pyrophosphate-extractable HS exhibited higher molecular weights than those extractable by $\mathrm{NaOH}$.

(6) Molecular-size classification of isolated soil HS by online MST-UF (standardized experimental conditions presupposed) can be considered as a simple and efficient procedure for their fractionation.

Table 3. Values of $\mathrm{E}_{350} / \mathrm{E}_{550}$ ratio in the six molecular weight fractions, separated by MST-UF.

\begin{tabular}{|c|c|c|c|c|c|c|}
\hline $\begin{array}{l}\text { Fraction: } \\
\text { Sample }\end{array}$ & $<1 \mathrm{kDa}$ & $1-5 \mathrm{kDa}$ & $5-10 \mathrm{kDa}$ & $10-50 \mathrm{kDa}$ & $50-100 \mathrm{kDa}$ & $>100 \mathrm{kDa}$ \\
\hline OX-HA-N & $\mathrm{n} \mathrm{m}$ & $\mathrm{n} \mathrm{m}$ & 11.7 & 7.2 & 6.8 & 5.14 \\
\hline OX-FA-N & 19.1 & 11.7 & 9.8 & 12.9 & 8.7 & 8.4 \\
\hline OX-FA-P & n.m & 17.2 & 16.1 & 11.1 & 10.4 & 10.2 \\
\hline MO-HA-N & n.m & n.m & 11.3 & 10.0 & 9.2 & 7.4 \\
\hline MO-FA-N & 15.8 & 11.7 & 11.6 & 8.3 & 8.6 & 5.4 \\
\hline MO-HA-P & $\mathrm{n} \mathrm{m}$ & n.m & $\mathrm{nm}$ & n.m & 5.4 & 4.2 \\
\hline MO-FA-P & 15.1 & 8.2 & 7.9 & 7.5 & 5.9 & 5.6 \\
\hline
\end{tabular}

Legend: see Table 2. n.m.: not measurable (no HS was separated in the given fraction). 


\section{Acknowledgements}

DPD is gratefull to Prof. Dr. D. Klockow for the invitation to work in ISAS, and to DAAD (GR) and FAPERGS (BR) for the financial support during her stay in Germany.

\section{References}

1. Swift, R.S. In Methods of soil analysis. Part 3. Chemical methods. Sparks, D.L., Ed., SSSA, Madison, 1996, p.1011-1069.

2. Stevenson, F.J. Humus Chemistry. Genesis, Composition, Reactions. 2nd. Edition. John Wiley: New York, 1994, 496p.

3. Parfitt, R.L.; Fraser, A.R.; Farmer, V.C. J.Soil Sci. 1977, 28, 289.

4. Tipping, E. Geochim. Cosmochim. Acta 1981, 45, 191.

5. Gu, B.; Schmitt, J.; Chen, Z. Lang, L.; MaCcarthy, J.F. Environ. Sci. Technol. 1994, 28, 38.

6. Schuppli, P.; Ross, G.J.; McKeague, J.A. Soil Sci. Soc. Am. J. 1983, 47,1026.

7. Kaiser, K.; Zech, W. Soil Sci. 1996, 161, 452.

8. Schulten, H.R.; Leinweber, P. Soil Sci. Soc. Am.J. 1995, 59, 1019.

9. Schulthess, C.P.; Huang, C.P. Soil Sci. Soc. Am. J. 1991, 55, 34.

10. Varadachari, C.; Mondal, A.H.; Ghosh, K. Soil Sci. 1995, 159, 185.

11. Singer, A.; Huang, P.M. Soil Sci. Soc. Am. J. 1993, 57, 271.

12. Senesi, N.; Miano, T.M.; Brunetti, G. Quim. Anal. 1994, 13, 26.

13. Schnitzer, M.; Schuppli, P. Can. J. Soil Sci. 1989, 69, 253.

14. Clapp, C.E.; Hayes, M.H.B. In Humic substances and organic matter in soil and water environments: Characterization, transformations and interactions. Clapp, C.E.; Hayes, M.H.B; Senesi, N.; Griffith, S.M., Eds.; IHSS, Birmingham, UK, 1996, p. 3.
15. Hayes, T.M.; Hayes, M.H.B.; Skjemstad, J.O.; Swift, R.S.; Malcolm, R.L. In Humic substances and organic matter in soil and water environments: Characterization, transformations and interactions. Clapp, C.E.; Hayes, M.H.B; Senesi, N.; Griffith, S.M., Eds.; IHSS, Birmingham, UK, 1996, p. 13.

16. Kawahigashi, M.; Fujitake, N.; Takahashi, T. Soil Sci. Plant Nutr. 1995, 42, 355.

17. Burba, P.; Shkinev,V.; Spivakov, B.Y. Fresenius J. Anal. Chem. 1995, 351, 74.

18. Aster, B.; Burba, P.; Broekaert, J.A.C. Fresenius J. Anal. Chem. 1996, 354, 722.

19. Bayer, C. Dynamics of soil organic matter in different management systems. Porto Alegre, Agronomy Faculty, UFRGS, 1996, 210 p. PhD Thesis.

20. Albuquerque, J.A. Susceptibility of soils of Rio Grande do Sul to interrill soil erosion. Porto Alegre, Agronomy Faculty, UFRGS, 1998, 156p. PhD Thesis.

21. Bloom, P.R.; Leenheer, J.A. In Humic substances II: In search of structure; Hayes, M.H.B.; MacCarthy, P.; Malcolm, R.L.; Swift, R.L., Eds.; John Wiley, Chichester 1989. p. 411.

22. Murphy, E.M.; Zachara, J.M. Geoderma, 1995, 67, 103.

23. Chen, Y.; Senesi, N.; Schnitzer, M. Soil Sci. Soc. Am. J. 1977, 41, 352.

24. Tan, K.H.; Lobartini, J.C.; Himmelsbach, D.S.; Asmussen, L.E. Commun. Soil Sci. Plant Anal. 1991, 22, 861.

25. Pang, L.S.K.; Vassalo, A.M.; Wilson, M.A. Org. Geochem. 1990, 16, 853.

26. Kipton, H.; Powell, J.; Town, R.M.; Anal. Chim. Acta 1992, 267, 47.

27. Summers, R.S; Cornel, P.K.; Roberts, P.V. Sci. Total Environ. 1987, 62, 27.

28. Chin, Y.; Alken, G.; O‘Loughlin, E. Environ. Sci. Technol. 1994, 28, 1853. 